\title{
EVENTOS DE CISALHAMENTO E MINERALIZAÇÃO AURÍFERA NA REGIÃO NORDESTE DO QUADRILÁTERO FERRÍFERO: CONSIDERAÇÕES BASEADAS EM ANÁLISES U-PB DE RUTILO E TITANITA
}

\author{
Carlos Mauricio Noce(*) \& Nuno Machado(**)
}

\begin{abstract}
$\mathrm{U}-\mathrm{Pb}$ analyses were carried out on rutile and titanite from sheared mafic volcanics and gneisses from northeastern Quadrilátero Ferrífero. Rutile growth is related to hydrothermal alteration and gold mineralization in the Nova Lima Group. Rutile analysis is $24 \%$ discordant and yield $207 \mathrm{~Pb} /$ $206 \mathrm{~Pb}$ age of $2580 \mathrm{Ma}$ whilst titanite in the gneiss is $3.5 \%$ discordant and yield $207 \mathrm{~Pb} / 206 \mathrm{~Pb}$ age of $2555 \mathrm{Ma}$. It can be concluded that a first episode of shearing and gold mineralization occurred during the Archean. This episode could not be precisely dated due to lead loss induced by Proterozoic events.
\end{abstract}

\section{INTRODUÇÃO}

A idade dos eventos tectono-termais e metalogenéticos, no Quadrilátero Ferrífero, constitui um tema de grande interesse geológico. Nos últimos anos, graças à obtenção de um considerável acervo de determinações $\mathrm{U}-\mathrm{Pb}$ para a região, os conhecimentos sobre o tema têm sido muito ampliados (Machado et al., 1992, Machado \& Carneiro, 1992, Noce, 1995, Machado et al., 1996, etc.). A evolução arqueana é marcada por diversos eventos tectono-termais e magmáticos, entre 2,9 e 2,6 Ga, embora os processos de geração crustal possam ser tão antigos quanto 3,5 Ga. No Proterozóico, a atuação do Evento Transamazônico (ca. 2,1-2,0 Ga) evidencia-se por processos metamórficos e magmáticos. $\mathrm{O}$ registro isotópico $\mathrm{U}-\mathrm{Pb}$ do Evento Brasiliano é muito pouco expressivo, embora seus efeitos no Quadrilátero Ferrífero sejam demonstrados pelos estudos estruturais de Chemale Jr. et al., (1991) e de outros autores.

No presente trabalho, são apresentadas determinações $\mathrm{U}-\mathrm{Pb}$ em rutilo e titanita, provenientes de rochas cisalhadas da região nordeste do Quadrilátero Ferrífero. Objetivou-se obter informações sobre a idade de processos de cisalhamento e mineralização aurífera.

\section{SÍNTESEGEOLÓGICAE AMOSTRAGEM}

Os grandes rasgos geológicos da região em causa são representados pelo Complexo Gnáissico de Caeté, pelo Sinclinal Gandarela (constituído pelo Supergrupo Minas) e pela Serra das Cambotas, que representa a extensão meridional do Supergrupo Espinhaço. O arcabouço estrutural é definido por um sistema de falhas de empurrão e falhas oblíquas, as quais constituem o Sistema Cambotas-Fundão, detalhadamente descrito por
Chemale Jr. et al. (1991). Este sistema de falhamentos envolveu o Supergrupo Minas no Sinclinal Gandarela e porções do seu embasamento, representado na área pelo Grupo Nova Lima, posicionando o conjunto contra o próprio Grupo Nova Lima, a oeste, e o Complexo Caeté a norte. Esta situação pode ser visualizada no mapa da figura 1, extraído de Belo de Oliveira \& Vieira (1987). O mapa delimita um domínio alóctone e outro paraautóctone para o Grupo Nova Lima (Supergrupo Rio das Velhas). O primeiro corresponde à faixa desta unidade que foi envolvida pelo Sistema CambotasFundão. Internamente a este domínio, Belo de Oliveira \& Vieira (1987) identificaram uma mega-estrutura antiformal, fortemente acilíndrica (estrutura Geriza), composta por metavulcânicas máficas e ultramáficas (fig. 1).

Na estrutura Geriza, especialmente em seus bordos falhados e cisalhados, encontram-se diversas ocorrências auríferas. A mineralização aurífera associase a processos de alteração hidrotermal nas zonas de cisalhamento (Belo de Oliveira et al., 1990). As metavulcânicas máficas, nas zonas de cisalhamento mineralizadas, evidenciam reações de sericitização, cloritização e carbonatação. No âmbito deste processo, ocorreu a formação de rutilo a partir da ilmenita préexistente.

Uma fração de rutilo, extraída de amostra proveniente de uma zona mineralizada localizada no bordo sul da estrutura Geriza, foi fornecida por O. A. Belo de Oliveira (DOCEGEO) e analisada no presente trabalho. A localização da amostra (amostra CAE-1) encontra-se na figura 1 .

Uma outra amostra da região em foco provém de uma pedreira próxima à localidade de Cocais (amostra 
M-88-8C, fig. 1). Ocorre aí um gnaisse intensamente cisalhado e com bandas máficas, de onde obteve-se uma fração de titanita. também admitem que as idades mais novas do rutilo, em relação a outros minerais, possam representar idades de resfriamento, ou sua formação nos estágios finais

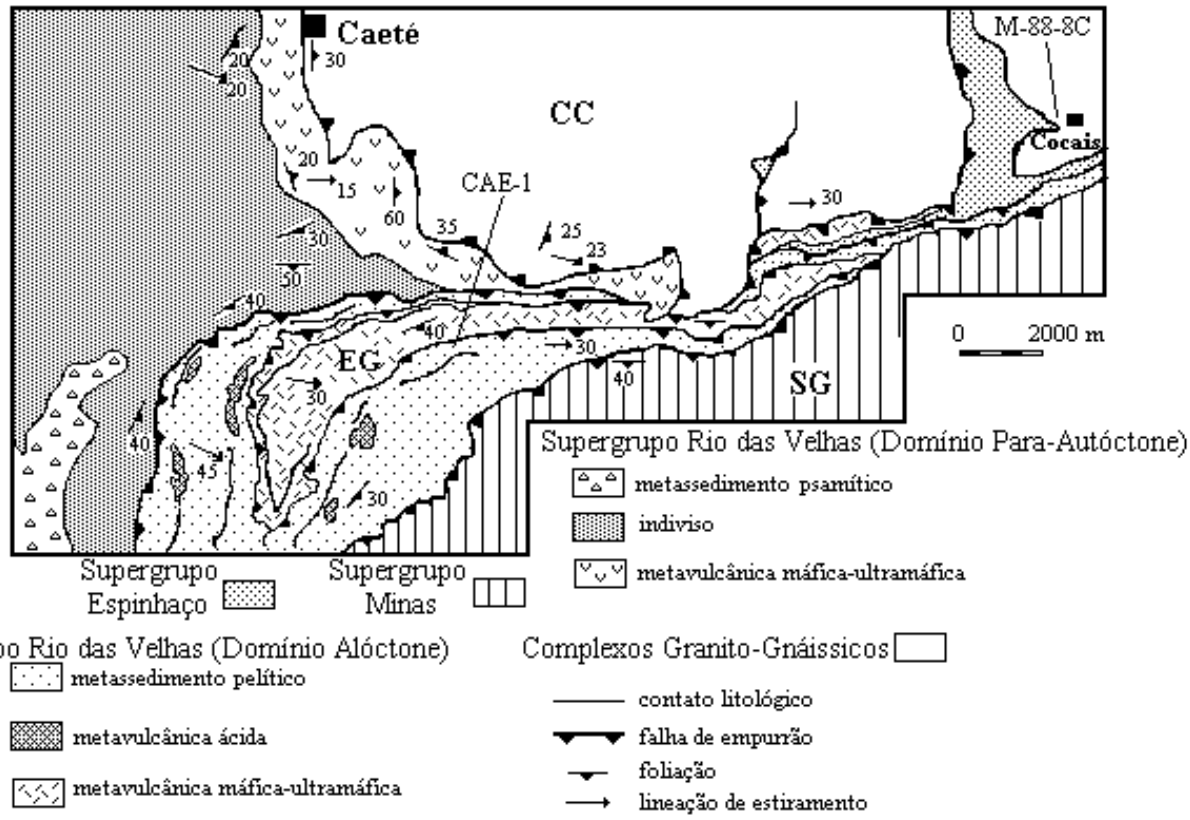

CC - Complexo Caeté; SG - Sirclinal Gardarela; EG - Estrut ura Geriza CAE1 - localizaçäo de armostra

Figura 1: Mapa geológico da região de Caeté (segundo Belo de Oliveira \& Vieira, 1987). Figure 1: Geologic map of Caeté region (after Belo de Oliveira \& Vieira, 1987).

\section{GEOCRONOLOGIA}

\section{Determinações U-Pb em rutilo e resultados obtidos}

Embora possa ser encontrado em algumas rochas ígneas, especialmente em rochas alcalinas e pegmatitos, o rutilo é muito mais comum nas rochas metamórficas. Rutilo metamórfico tem sido descrito em uma grande variedade de litotipos, abrangendo praticamente todos os graus metamórficos (Mezger et al., 1989). Quando comparado com outros minerais, como zircão, monazita e titanita, a utilização do rutilo em estudos geocronológicos $\mathrm{U}-\mathrm{Pb}$ é relativamente rara na literatura geológica. O comportamento do sistema isotópico U$\mathrm{Pb}$ neste mineral é bastante complexo, frequentemente resultando em idades muito discordantes e de difícil interpretação (e.g. Corfu \& Muir, 1989).

Um aspecto comum ao estudo geocronológico de cinturões metamórficos de diversas idades é o fato de o rutilo, sistematicamente, fornecer idades mais novas que o zircão e mesmo que a titanita. Diferenças de até 200 Ma já foram observadas. Mezger et al. (1989) apresentam um estudo desta natureza para dois terrenos de alto grau do Arqueano e do Mesoproterozóico, onde concluem que as idades de rutilo são idades de resfriamento, sendo semelhantes às idades K-Ar e ArAr em hornblenda para as mesmas áreas. Com base nesta conclusão, calcularam a temperatura de fechamento do rutilo, em relação ao sistema U-Pb, em $400 \pm 20^{\circ} \mathrm{C}$. Em outros trabalhos, Schärer et al. (1986) e Davis et al. (1989) do evento metamórfico principal. Entretanto, estes autores inclinam-se para a hipótese de que o rutilo tenha sido gerado em um evento metassomático posterior ao metamorfismo.

As situações onde o rutilo é, com certeza, um produto de reações hidrotermais, têm sido mais frequentemente tratadas na literatura, com o objetivo de se datar estes processos e as mineralizações sulfetadas associadas (e.g. Richards et al., 1988, Wong et al., 1989, Corfu \& Muir, 1989, Schandl et al., 1990). Datações bastante precisas do evento hidrotermal gerador do rutilo têm sido obtidas, embora nem sempre este evento relacione-se diretamente com a mineralização, que pode ser mais antiga (Corfu \& Muir, 1989). Ficou também demonstrado que o rutilo hidrotermal pode formar-se a temperaturas consideravelmente mais baixas que a temperatura de bloqueio calculada por Mezger et al., (1989). Neste caso, a idade obtida deve datar a cristalização do mineral (Schandl et al., 1990).

Os rutilos estudados no presente trabalho são de origem hidrotermal e, aparentemente, relacionados ao processo de mineralização aurífera. A fração analisada era composta por cristais bem formados, de hábito prismático e cor marron escura. Por serem os grãos muito opacos, não foi possível identificar a presença de inclusões. A fração foi submetida à abrasão por $1 \mathrm{~h}$ a uma pressão de 2 psi. Os resultados analíticos são apresentados na tabela 1 e figura 2 . A análise é muito discordante $(24 \%)$ e com idade mínima $(207 \mathrm{~Pb} / 206 \mathrm{~Pb})$ 
de 2580 Ma. O conteúdo em U era extremamente baixo, $3,2 \mathrm{ppm}$, sendo a razão $206 \mathrm{~Pb} / 204 \mathrm{~Pb}$ igualmente muito baixa, igual a 70. Isto aumenta a incerteza da idade, tornando necessário fazer a correção para o $\mathrm{Pb}$ comum. Esta foi feita assumindo uma composição isotópica inicial a partir da curva de crescimento do $\mathrm{Pb}$ de Stacey \& Kramers (1975) para T=2776 Ma. Esta idade foi tomada do principal evento arqueano datado na região (Machado et al., 1992). Ainda que arbitrária, tal correção não tem qualquer influência na informação básica fornecida pela análise, a de que o rutilo deve ter cristalizado durante o Arqueano.

Existe outra análise de rutilo para uma área próxima, no Complexo Caeté (Machado et al., 1992). O rutilo provém de uma rocha gnássica milonitizada, cuja idade de cristalização, obtida a partir de análise de zircão, é 2776+7/-6 Ma. O rutilo era também pobre em U (6 ppm) fornecendo idade mínima de $2309 \mathrm{Ma}$, muito discordante (fig. 2). Belo de Oliveira \& Teixeira (1990) obtiveram, para outra faixa de gnaisses milonitizados do Complexo Caeté, idade Rb-Sr de 2130ะ101 Ma., interpretada como a idade do metassomatismo associado à milonitização. Esta idade é coerente com os dados U-Pb para o metamorfismo transamazônico no Quadrilátero Ferrífero (Machado et al., 1992, Noce,
1995). Tal evento teria causado perda parcial de $\mathrm{Pb}$ no rutilo do gnaisse, mas a cristalização deste mineral está ligada a um evento mais antigo.

Conclusão semelhante pode ser admitida para o rutilo da zona mineralizada da estrutura Geriza. A discordância da análise indica um padrão complexo de perda de $\mathrm{Pb}$, devido à influência dos eventos proterozóicos. Entretanto, sua formação estaria relacionada a um episódio de alteração hidrotermal ocorrido ainda no Arqueano. Um cenário plausível é que, durante este primeiro evento, todos os minerais reativos para a formação do rutilo tenham sido consumidos. Logo, no caso da recorrência dos processos de alteração, rutilo não mais se formaria, embora seu sistema isotópico tenha sido afetado.

As conclusões a partir deste único dado devem ser tomadas com a devida cautela. Uma recomendação para futuras investigações nesta linha pode ser tomada do trabalho de Corfu \& Muir (1989). Partindo de uma análise muito discordante, os autores separaram frações menores de rutilo da mesma amostra, sob criteriosa classificação tipológica, obtendo resultados muito mais concordantes, especialmente para rutilos translúcidos onde a presença de inclusões pode ser detectada (e evitada).

\begin{tabular}{|c|c|c|c|c|c|c|c|c|c|c|c|c|c|}
\hline \multicolumn{3}{|c|}{ Amostra } & \multicolumn{3}{|c|}{ Concentrações } & \multicolumn{5}{|c|}{ Razões Isotópicas } & \multicolumn{3}{|c|}{ Idades (Ma) } \\
\hline $\begin{array}{c}\mathrm{N}^{\circ} \text { da } \\
\text { amostra }\end{array}$ & $\underset{* 1}{\text { Mineral }}$ & $\begin{array}{l}\text { Peso } \\
(\mathrm{mg})\end{array}$ & $\begin{array}{l}\text { Urânio } \\
\left(\mathrm{ppm}_{2}\right)^{*}\end{array}$ & $\begin{array}{c}\mathrm{Pb} \text { rad. } \\
(\mathrm{ppm}) \\
* 2\end{array}$ & $\begin{array}{l}\mathrm{Pb} \text { com. } \\
(\mathrm{pg})^{* 3}\end{array}$ & $\begin{array}{c}{ }^{206} \mathrm{~Pb} /{ }^{204} \mathrm{P} \\
\mathrm{b}^{* 4}\end{array}$ & $\begin{array}{c}{ }^{208} \mathrm{~Pb} /{ }^{206} \mathrm{~Pb} \\
* 5\end{array}$ & $\begin{array}{c}{ }^{206} \mathrm{~Pb} /{ }^{238} \mathrm{U} \\
* 5\end{array}$ & $\begin{array}{c}{ }^{207} \mathrm{~Pb} /{ }^{235} \mathrm{U} \\
\end{array}$ & $\begin{array}{c}{ }^{207} \mathrm{~Pb} /{ }^{206} \mathrm{~Pb} \\
* 5\end{array}$ & ${ }^{206} \mathrm{~Pb} /{ }^{238} \mathrm{U}$ & ${ }^{207} \mathrm{~Pb} /{ }^{235} \mathrm{U}$ & ${ }^{207} \mathrm{~Pb} /{ }^{206} \mathrm{~Pb}$ \\
\hline $\begin{array}{l}\text { CAE-1 } \\
\text { M-88-8c }\end{array}$ & $\begin{array}{l}R \\
T\end{array}$ & $\begin{array}{l}0,1710 \\
0,2800\end{array}$ & $\begin{array}{c}3,21 \\
78\end{array}$ & $\begin{array}{c}3,30 \\
42\end{array}$ & $\begin{array}{c}231 \\
1041\end{array}$ & $\begin{array}{c}70 \\
635 \\
\end{array}$ & $\begin{array}{l}2,0106 \\
0.1423\end{array}$ & $\begin{array}{l}0,37406 \\
0,46914\end{array}$ & $\begin{array}{c}8,886 \\
10,978\end{array}$ & $\begin{array}{l}0,17230 \\
0,16972\end{array}$ & $\begin{array}{l}2048 \\
2480\end{array}$ & $\begin{array}{l}2326 \\
2521\end{array}$ & $\begin{array}{l}2580 \\
2555\end{array}$ \\
\hline
\end{tabular}

*1- R=rutilo; $\mathrm{T}=$ titanita

*2- Concentrações são conhecidas com precisão de $2 \%$ para amostras pesando $0,4 \mathrm{mg}, 10-20 \%$ para amostras abaixo de 0,020mg. Para amostras cujo peso está abixo da sensibilidade da balança, $0,001 \mathrm{mg}$, as concentrações listados são valores máximos.

*3- $\mathrm{Pb}$ comum total corrigido para $\mathrm{o} \mathrm{Pb}$ comum do spike.

*3- $\mathrm{Pb}$ comum total corrigido para o $\mathrm{Pb}$ comum do spike.
*4- Razão medida, corrigida apenas para o fracionamento.

*4- Razão medida, corrigida apenas para o fracionamento.

Tabela 1: Resultados analíticos U-Pb para rutilo e titanita da região nordeste do Quadrilátero Ferrífero. Table 1: U-Pb analitical results for rutile and titanite in NE Quadrilátero Ferífero.

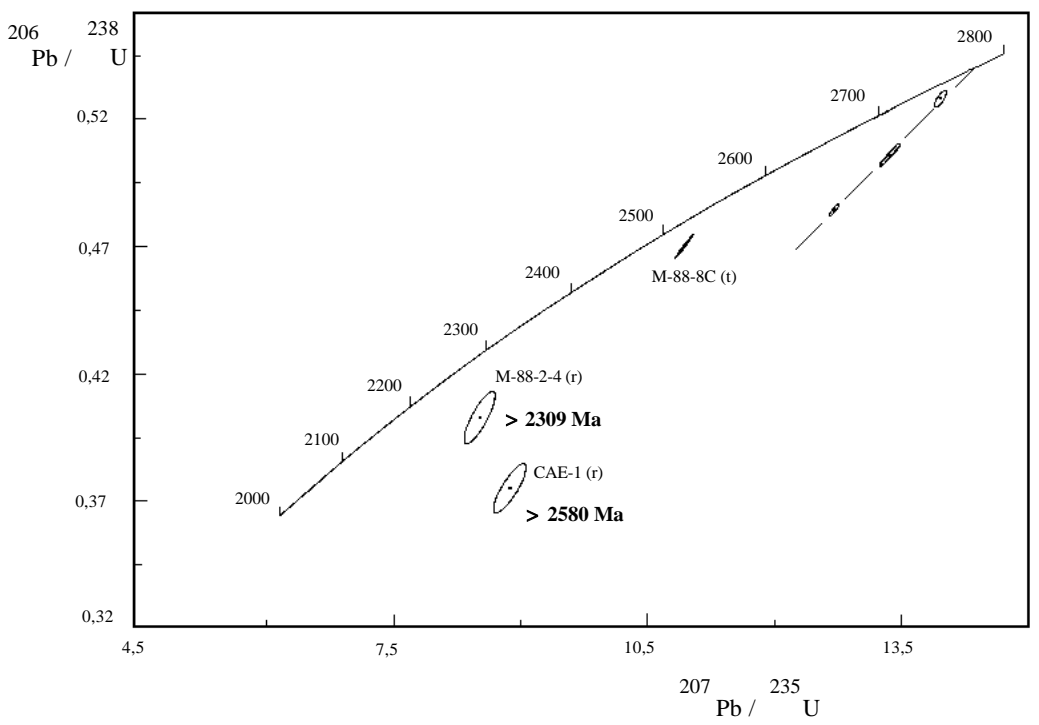

Figura 2: Diagrama concórdia para o rutilo da zona mineralizada no Grupo Nova Lima (CAE-1) e titanita da Pedreira de Cocais (M-88-8C). São também lançados a discórdia do Gnaisse de Caeté (intercepto superior a $2776 \mathrm{Ma}$ ) e o rutilo desta mesma rocha (M-88-2-4).

Figure2: Concórdia diagram for rutile of grupo Nova Lima (CAE-1) and titanite of Cocais (M-88-8C). Discordia line for Caeté Gnaisse (upper cut in $2776 \mathrm{Ma}$ ) and for the rutile of this roch (M88-2-4). 


\section{Determinação U-Pb em titanita do gnaisse de Cocais}

A fração de titanita analisada forneceu uma idade mínima de $2555 \mathrm{Ma}, 3,5 \%$ discordante (tab. 1, fig. 2). Tentativamente, este resultado poderia colocar-se em uma discórdia entre o Arqueano, a 2800-2700 Ma, e o Evento Transamazônico, ca. 2050 Ma. Na hipótese de ser correta esta assertiva, ter-se-ia uma situação semelhante à verificada nos gnaisses do Complexo Belo Horizonte, ou seja, o Evento Transamazônico como o principal episódio de retrabalhamento das rochas arqueanas (Noce, 1995).

\section{CONCLUSÕES}

O rutilo e a titanita analisados, ambos provenientes de zonas de cisalhamento, foram gerados em evento(s) metamórfico/metassomático(s) do Arqueano. Embora a estruturação desta região se deva, essencialmente, aos eventos tectônicos do Proterozóico (Belo de Oliveira \& Teixeira 1990, Chemale Jr. et al., 1991), algumas zonas de cisalhamento seriam estruturas arqueanas reativadas.

Os dados isotópicos para o rutilo indicam que o primeiro evento de cisalhamento/alteração hidrotermal na estrutura Geriza, com mineralização aurífera associada, é de idade arqueana. Tal conclusão é coerente com os resultados de determinações $\mathrm{Pb}-\mathrm{Pb}$ em sulfetos da Mina de São Bento (Dewitt et al., 1994), situada pouco a leste desta área. Admite-se que os processos metalogenéticos tenham sido recorrentes durante os eventos proterozóicos, de forma que a mineralização aurífera não pode ser atribuida a um único episódio.

\section{REFERÊNCIASBIBLIOGRÁFICAS}

BELO de OLIVEIRA, O.A. \& VIEIRA, M.B.H. 1987. Aspectos da deformação dúctil e progressiva no Quadrilátero Ferrífero. In: SIMPÓSIO DE GEOLOGIA DE MINAS GERAIS, 4, Belo Horizonte, 1987. Anais... Belo Horizonte, SBG-MG, p.237-252 (Boletim 5).

BELO de OLIVEIRA, O.A. \& TEIXEIRA, W. 1990. Evidências de uma tectônica tangencial proterozóica no Quadrilátero Ferrífero, MG. In: CONGRESSO BRASILEIRO DE GEOLOGIA, 36, Natal, 1990. Anais...Natal, SBG, p.2589-2603.

BELO de OLIVEIRA, O.A.; VIEIRA, M.B.H.; GRECO, F.M. 1990. Alteração hidrotermal relacionada a zonas de cisalhamento dúctil em depósitos auríferos no Quadrilátero Ferrífero. In: CONGRESSO BRASILEIRO DE GEOLOGIA, 36, Natal, 1990. Boletim de Resumos...Natal, SBG, p.101.

CHEMALE JR., F.; ROSIÈRE, C.A.; ENDO, I. 1991. Evolução tectônica do Quadrilátero Ferrífero Minas Gerais-Um modelo. Pesquisas, 18(2):104-127.

CORFU, F. \& MUIR, T.L. 1989. The Hemlo-Herron Bay greenstone belt and Hemlo Au-Mo deposit, Superior province, Ontario, Canada, 2: Timing of metamorphism, alteration and $\mathrm{Au}$ mineralization from titanite, rutile and monazite U-Pb geochonology. Chemical Geology, 79:201-223.

DAVIS, D.W.; POULSEN, K.H.; KAMO, S.L. 1989. New insights into Archean crustal development from geochronology in the Rainy Lake area, Superior Province, Canada. Journal of Geology, 97:379-398.

DEWITT, E.; LANDIS, G.P.; ZARTMAN, R.E.; THORMAN, C.H.; GARAYP, E.; PEREIRA, S.M.; BUENO DO PRADO, M.G., VIEIRA, F.W.R. 1994. Isotopic and fluid inclusion data on the age of the São Bento and Morro Velho gold deposits, Minas Gerais, Brazil. Internal report, $5 \mathrm{p}$.

MACHADO, N. \& CARNEIRO, M.A. 1992. U-Pb evidence of late Archean tectono-thermal activity in the southern São Francisco shield, Brazil. Canadian Journal of Earth Sciences, 29:2341-2346.

MACHADO, N.; NOCE, C.M.; LADEIRA, E.A.; BELO DE OLIVEIRA, O.A. 1992. U-Pb geochronology of Archean magmatism and Proterozoic metamorphism in the Quadrilátero Ferrífero, southern São Francisco Craton, Brazil. Geological Society of America Bullettin, 104:12211227.

MACHADO, N.; SCHRANK, A.; NOCE, C.M.; GAUTHIER, G. 1996. Ages of detrital zircon from ArcheanPaleoproterozoic sequences: Implications for Greenstone Belt setting and evolution of a Transamazoniam foreland basin in Quadrilátero Ferrífero, southeast Brazil. Earth and Planetary Science Letters, 141:259-276.

MEZGER, K.; HANSON, G.N.; BOHLEN, S.R. 1989. Highprecision $\mathrm{U}-\mathrm{Pb}$ ages of metamorphic rutile: application to the cooling history of high-grade terranes. Earth and Planetary Science Letters, 96:106-118.

NOCE, C.M. 1995. Geocronologia dos eventos magmáticos, sedimentares e metamórficos na região do Quadrilátero Ferrífero, Minas Gerais. São Paulo, 128 p. (Tese de Doutoramento, Universidade de São Paulo).

RICHARDS, J.P.; KROGH, T.E.; SPOONER, E.T.C. 1988. Fluid inclusion characteristics and $\mathrm{U}-\mathrm{Pb}$ rutile age of late hydrothermal alteration and veining at the Musoshi stratiform cooper deposit, Central Africa cooper belt, Zaire. Economic Geology, 83:118-139.

SCHANDL, E.S.; DAVIS, D.W.; KROGH, T.E. 1990. Are the alteration halos of massive sulfide deposits syngenetic? Evidence from $\mathrm{U}-\mathrm{Pb}$ dating of hydrothermal rutile at the Kidd volcanic center, Abitibi subprovince, Canada. Geology, 18:505-508.

SCHÄRER, U.; KROGH, T.E.; GOWER, C.F. 1986. Age and evolution of the Grenville Province in eastern Labrador from U-Pb systematics in accessory minerals. Contributions to Mineralogy and Petrology, 96:438-451.

STACEY, J.S. \& KRAMERS, J.D. 1975. Approximation of terrestrial lead isotope evolution by a two-stage model. Earth and Planetary Science Letters, 26:207-221.

WONG, L.; DAVIS, D.W.; HANES, J.A.; ARCHIBALD, D.A.; HODGSON, C.J.; ROBERT, F. 1989. An integrated U$\mathrm{Pb}$ and Ar-Ar geochronological study of the Archean Sigma gold deposit, Val d'Or, Quebec. In: ANNUAL MEETING OF THE GEOLOGICAL ASSOCIATION OF CANADA AND MINERALOGICAL ASSOCIATION OF CANADA, 14, Montreal, 1989. Abstracts...Montreal, GAC-MAC, p.45A. 